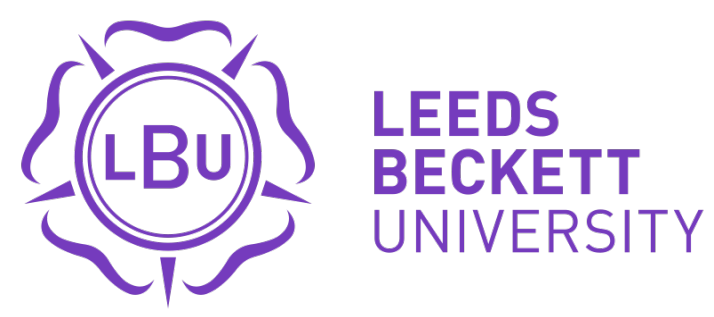

Citation:

Morley, D and Morgan, G and McKenna, J and Nicholls, AR (2014) Developmental contexts and features of elite academy football players: Coach and player perspectives. International Journal of Sports Science and Coaching, 9 (1). 217 - 232. ISSN 1747-9541 DOI: https://doi.org/10.1260/17479541.9.1.217

Link to Leeds Beckett Repository record:

https://eprints.leedsbeckett.ac.uk/id/eprint/141/

Document Version:

Article (Published Version)

The aim of the Leeds Beckett Repository is to provide open access to our research, as required by funder policies and permitted by publishers and copyright law.

The Leeds Beckett repository holds a wide range of publications, each of which has been checked for copyright and the relevant embargo period has been applied by the Research Services team.

We operate on a standard take-down policy. If you are the author or publisher of an output and you would like it removed from the repository, please contact us and we will investigate on a case-by-case basis.

Each thesis in the repository has been cleared where necessary by the author for third party copyright. If you would like a thesis to be removed from the repository or believe there is an issue with copyright, please contact us on openaccess@leedsbeckett.ac.uk and we will investigate on a case-by-case basis. 


\title{
Developmental Contexts and Features of Elite Academy Football Players: Coach and Player Perspectives
}

\author{
David Morley', Gareth Morgan', Jim McKenna1 \\ and Adam R. Nicholls ${ }^{2}$ \\ ${ }^{1}$ Institute of Sport, Physical Activity and Leisure \\ Leeds Metropolitan University, \\ Headingley, Leeds, LS6 3QS, UK \\ E-mail: D.Morley@leedsmet.ac.uk \\ 2Department of Sport, Health and Exercise Science, \\ University of Hull, HU6 7RX, UK
}

\begin{abstract}
Player profiling can reap many benefits; through reflective coach-athlete dialogue that produces a profile the athlete has a raised awareness of their own development, while the coach has an opportunity to understand the athlete's viewpoint. In this study, we explored how coaches and players perceived the development features of an elite academy footballer and the contexts in which these features are revealed, in order to develop a player profile to be used for mentoring players. Using a Delphi polling technique, coaches and players experienced a number of 'rounds' of expressing their opinions regarding player development contexts and features, ultimately reduced into a consensus. Players and coaches had differing priorities on the key contexts of player development. These contexts, when they reflect the consensus between players and coaches were heavily dominated by ability within the game and training. Personal, social, school, and lifestyle contexts featured less prominently. Although 'discipline' was frequently mentioned as an important player development feature, coaches and players disagreed on the importance of 'training'.
\end{abstract}

Key words: Elite Football Academy Coaches, Player Development, Player Profiling, Soccer, Talent Development

\section{INTRODUCTION}

In this study, we aimed to explore players' and coaches' perceptions of the most appropriate player development contexts and features to be used within a mentoring programme to profile and support players within an elite football academy. The research was set in a talent development environment, so the following review provides a brief overview of how 
talented players in sport have been characterised previously. We subsequently outline the emergence of player profiling as a tool to monitor and support players in relation to predetermined characteristics. This is followed by an examination of the influences players could experience within a number of environments and concludes with a description of the research context to provide a rich and vivid portrayal of the environment in which the participants were situated.

\section{DEFINING 'PLAYER DEVELOPMENT FEATURES' WITHIN TALENT DEVELOPMENT}

The modelling of athletes showing potential to achieve a high level of proficiency in sport (commonly termed as 'talent development') has accelerated rapidly over the past decade. While many authors seek to bring clarity to a highly complex debate [1-4], talent development is fundamentally concerned with the strategies and practices aimed at the maximisation of athletic performance. However, talent development models vary widely and are constructed around a range of disciplines and perspectives with a wide range of inherent player development features. For example, Balyi and Hamilton's [5] model of Long-Term Athlete Development relies heavily on physiological perspectives associated with adolescent growth. In contrast, multiplicative models of talent development recognise the complexity of the athlete themselves and the context in which they exist, to counteract the failings of uni-dimensional approaches, and more effectively represent the fluidity of talent in sport [6].

The importance of examining the contexts in which youth activity occurs has been documented elsewhere [7] and provides substance to the exploration of player development contexts (PDCs) in this research. However, the process of identifying which 'holistic' qualities are most pertinent to a specific context has received scant attention within the literature, with Larsen et al.'s use of an ecological premise to understanding talent development offering an exception to the rule [8]. Their work identified that coaches, players and parents agreed that goal-setting, self-awareness and showing respect were key skills in the player realising their potential.

\section{PLAYER PROFILING}

The basic premise of player profiling is to maximise performance, which aligns with the core aim of talent development. Typically, talent development models emphasise the perceived requirements for 'core competencies' or 'dispositions' of expert athletes and how these need to be developed in relation to a constantly changing set of 'environmental factors' in a range of contexts. Player profiling is inextricably linked with this modelling process in the way that it draws from the various models, asking players to rate themselves according to a series of pre-determined competencies [9, 10]. For Jones [11], the player profile has three main purposes: 1) to aid in identifying an appropriate intervention, 2) to maximise the performer's motivation and adherence to the programme, and 3) to monitor any changes over time. As previous research has identified a positive link between self-regulation and performance levels of youth soccer players [12], the need for players to take more control and ownership of their own development is paramount.

\section{INFLUENCES ON PLAYER DEVELOPMENT}

When considering the elements of a player profiling tool, it is important to understand what influences a player's development across the wider range of environments that they encounter, at any given developmental stage. What is instantly obvious within these 
influences is the suggestion that player development involves recognition that the player's ability is multifaceted. For example, the United Kingdom's National Curriculum for Physical Education [13] assesses students within a statutory framework in a number of domains, including being able to demonstrate cognitive, physical and social competencies across a number of key concepts and themes. Furthermore, the UK Coaching Framework [14] outlines a model that explicitly highlights the need to differentiate provision according to aspiration; e.g., participant, children, talented and high performance. Inevitably, this raises questions about how to cater for each of these populations. Recently, Sports Coach UK published a support document for children's coaches [15], clearly articulating the employment of an abridged version of the 5 C's (Connection, Caring, Confidence, Character, Creativity). More closely related to our study is the English Football Association's (FA's) (the National Governing Body for football in England) use of a 'four-corner' model of player development; ie., Technical, Physical, Psychological, and Social [16].

While each of these models underlines the need to commit resources to develop a multifaceted and holistic portrayal of the developing player, there is less commitment to the generation of data to evidence the impact of such modelling.

Another potential influence was launched during the research, when the Premier League introduced the Elite Player Performance Plan (EPPP) and coaches involved in the study were exploring ways to address the demands of this new plan. Ged Roddy, Director of Youth at the Premier League, suggested the EPPP "will raise the intensity of the Academy system, leading to improved education and career support programmes being rolled out to ensure every player is provided with holistic support for all of his development" [17]. The EPPP report [18] goes further by suggesting: "The successful delivery of the EPPP is predicated on placing the player at the centre of the process... in which the player can fully achieve his potential" [18, p. 72], with regulation demanding that "Academies will develop programmes which reflect the social and holistic development programme of players and introduce a programme of staff CPD to support this" [18, p. 74].

\section{RESEARCH CONTEXT}

The current research was conducted within the Academy of a professional football club with a prolific record of achievement in the English Premier League and in European competitions. The research began with a consultancy team being asked to provide services to support Academy players and coaches to develop a mentoring process. This support was to be used formally - within the allocated weekly one-to-one mentoring sessions - and informally - during training sessions, games, and in day-to-day interactions between coaches and players. The consultancy team consisted of a project lead with expertise in talent development and working with children and young people; an e-learning consultant, and three academics with experience of coaching football in elite English Academies.

During early discussions with the coaching team, they clearly identified a need to increase the player's ownership of, and engagement with, their development by improving players' capacity for self-regulation. Coaches also discussed the paramount importance of adopting what they termed as a 'full-view' perspective of each player's development, as a way of better understanding the players' needs. For the coaches, a 'full-view' meant considering the players' wider developmental needs, beyond the actual playing of the game and training.

Players in the study were part of a Scholarship programme within the Academy and recruited by the Club from within the United Kingdom and internationally. These players resided in accommodation, also known as 'digs,' with an appointed carer. Many of the participants had played internationally at their appropriate age level. They attended school 
and integrated into its normal functions. However, teachers with responsibility for timetabling and curriculum delivery at the school were flexible with their programming to account for the playing and training commitments of the Academy players. Academy players were expected to play for the school team and engage in as many 'normal' school activities as possible, as this was viewed by the coaching and school staff as essential to their overall development. Coaches regarded participation in 'normal' activities, such as being part of a tutor group, participating in other extra-curricular clubs and attending school trips, as essential in keeping the players grounded.

Player participants all undertook a varied programme of activities, training most days and playing in school fixtures once a week, as part of the school's extra-curricular programme, and for the club at weekends. Younger players (11-15 years) would play in friendly fixtures arranged with other Premier League and Championship (the league below the Premier League) teams across the North of England, with older players (16-18 years) competing against the same teams in a more structured league. Typical training sessions involved technical and tactical development interspersed with a wider range of activities such as yoga, climbing, and aerobics. The seasonal demands of competition dictated the nature, frequency and intensity of these activities. Moreover, a training week would typically entail 5-6 practice sessions (approximately 8-12 hours, depending on age) as well as a scheduled game at the weekend, with this programme typically running from mid-July through to mid-June. The research team observed a close-knit and highly sociable community with high expectations in terms of punctuality, conformity to set procedures and etiquette, courtesy, and respect for others.

Player support was an integral feature of the academy with many features co-ordinated by an appointed Head of Education and Welfare. One of these features involved a weekly, 20minute, one-to-one mentoring session with their age-group coach that entailed completing a reflective written diary about diet, game and training experiences. The coaching team, comprising five coaches, were allocated specific responsibilities for coaching five age-group teams, Under 11s to Under 15s, in the Academy.

The consultancy team discussed the options for creating a more dynamic and engaging mentoring system with both coaches and players. The coaches expressed a strong need for a close examination of the core characteristics of a talented player so they could more fully support players in their holistic development across a range of contexts. The resulting process established what became known as Player Development Contexts (PDCs) and Player Development Features (PDFs) to be subsequently used for player profiling within a mentoring programme of this elite football academy; this paper records the process of constructing the profiling tool.

\section{METHOD}

\section{PARTICIPANTS}

Six male soccer players and five coaches from an English Premier League Football Academy participated in this study. Scholarship players ranged from 13 to 15 years of age, with the addition of an 18 year-old to offer a retrospective understanding of player development, given their longer-term experiences within the Academy (See Table 1 for more information). This purposive, convenience, sample [19] comprised six players, selected by the Academy coaches to represent a full range of player experiences that were part of the Scholarship scheme that consisted of twenty players. The coaches suggested that this group of scholarship players were in greater need than the other Academy players, given their 
circumstances. Once established, the profile could then be deployed with the wider group of Academy players. It was important to keep this group small as the players were also going to act as an advisory group for the design of the actual profiling tool. Coaches (36-64 years of age) had a range of expertise and experience (between 10-34 years of coaching). One was once an England Schoolboys Manager, responsible for a national team of school age players (Under 16s and Under 18s) selected through School, Regional and Area development squads. Others were experienced in coaching football with players of school age (5-16 years). All coaches had experience of coaching Academy football within a professional football club that had an Academy for Foundation (9-11 years), Youth Development (12-16 years), and Professional Development (17-21 years). Ethical approval was granted for the work, with parents giving consent and coaches and players giving assent to participation.

\section{MEASURES}

The Delphi Poll technique was an appropriate tool to use for this project as it facilitated the generation of a consensus [20] and had the potential to maximise engagement of the enduser. This engagement approach was favoured for involving both the players and coaches in capturing both groups' perceptions of player development.

The Delphi Poll technique has been used extensively in health and social sciences to gather opinions from experts in relation to a common theme, with the technique involving polling participants over a series of 'Rounds', whereby decisions are required to eliminate and/or cement responses from previous rounds to reach a consensus [21]. Although the Delphi is often conducted electronically, here the research team chose to administer Delphi Table 1. Players' Self-Descriptions of Their Age, Experience, and Expertise

\begin{tabular}{llllll} 
Participant 1 & Participant 2 & Participant $\mathbf{3}$ & Participant 4 & Participant $\mathbf{5}$ & Participant 6 \\
\hline 18 years of age, & U15s age group, & U15s age group, & U14s age group, & U14s age group, & U13s age group, elite \\
10/11 years & elite youth football & elite youth football & elite youth football & elite youth football & youth football with the \\
playing experience, & with various clubs & with the club & with the club & with the club & club academy since 6 \\
having signed for & since 7 years old & academy since 7 & academy since 7 & academy since 6 & years old, signed U9s \\
the Club when & & years old & years old, signed & years old, signed & \\
8 years old & & & U9s & U9s & \\
\hline
\end{tabular}

with the participants in situ, to maximise participant involvement and offer an opportunity to probe responses, where necessary.

Prior to deploying the Delphi Poll, the lead researcher delivered a mentoring workshop for the coaches at the Football Academy. This workshop identified that the coaches were interested in developing players across a number of what they described as specific 'contexts'. These contexts were subsequently labelled Player Development Contexts (PDCs). The nature of PDCs was discussed at length and it was agreed that they would be a suitable starting point for the Delphi Poll. The six PDCs identified by the coaches were:
1. Lifestyle
2. Personal
3. Social
4. Game
5. Training
6. School 
The next stage of the process quantified the perspectives of coaches and players on the player characteristics that would be developed within each context. A wide range of terms has already been used to describe these features, such as 'abilities', 'attributes' or 'dispositions' [22]. Whereas the term PDC emerged from conversations with coaches, the term PDF was more down to the research team referring to these aspects of development as 'features' within PDCs. The use of related terms emerged as a way of describing a number of contexts in which features of a player were exhibited or manifested. During the process of the research, this relationship was explained to coaches and players as 'here are a number of player development features that you might find in different contexts'.

\section{PROCEDURE}

Individually, each participant responded to the various rounds of the Delphi technique, with a researcher present to guide them through the process. Each round was separated by approximately two weeks. Within each round, questions were asked around the usefulness of the process, with field notes maintained at every stage. The following sections detail the processes involved in each round of the Delphi Poll.

Round 1 . The six previously agreed PDCs were presented to coaches and players and they were asked to 'rank the PDCs in order of priority $(1=$ top priority)'. Following this, participants offered their perspectives on what they believed the player development features' (PDFs) were within each of the six PDCs. For example, in the Lifestyle PDC, one coach commented, 'be disciplined about rest and lifestyle'.

Round 2. The research team analysed the Player Development Features (PDF) provided by the participants and excluded any repetitions. The remaining PDFs were then collated in a spread sheet, under an appropriate PDC, alongside a 5-point Likert scale (1= Strongly Agree, Agree, Unsure, Disagree, $5=$ Strongly Disagree). Participants were then invited to reconsider the PDFs within each PDC and score them using the Likert scale.

For each PDC, the research team calculated the mean score for each PDF. Any PDF that fell below the mean PDC score was eliminated. At this stage it became apparent that some PDCs contained substantially more PDFs than others. For example, the 'Personal' PDC contained 23 items, whereas the 'School' PDC contained only 12. To meet the end requirement of refining an on-going mentoring process, and appreciating that players could only reasonably focus on a limited number of PDFs, a more aggressive reduction strategy was then employed. Thresholds for retention were raised until the number of retained features was 10 or 11 PDFs per PDC.

Round 3. Participants were given a list of 10-11 PDFs for each PDC and asked to rank in order of priority. The mean of respondents' ranked priorities for PDFs was then calculated, resulting in a final ranked set of PDFs for inclusion in the mentoring process. To ensure the usability of PDFs within the mentoring process, the top 10 qualities were adapted to 'I' statements, e.g. 'I can...', 'I mix...', for the final mentoring tool.

\section{RESULTS}

Table 2 illustrates the coaches, players and combined priority ratings for the PDCs. Player, coach and combined mean average ratings and ranked priorities of the 6 different PDFs are presented in Table 3 (Lifestyle), Table 4 (Personal), Table 5 (Social), Table 6 (Game), Table 7 (Training) and Table 8 (School). 


\section{PDCs}

Training and Game PDCs feature prominently as high priorities of both coaches and players. Overall, Personal and Lifestyle are perceived as mid-order PDC priorities with Personal being ranked much higher by coaches than players. There is general agreement between both coaches and players that Social and School are low-order PDC priorities.

\section{LIFESTYLE}

With regard to lifestyle, players reported staying away from bad influences of alcohol and drugs, understanding the dangers of smoking and drinking, and being disciplined as the three most important lifestyle factors. Alternatively, coaches rated discipline higher, and then rest and nutrition as the most important factors that help players develop.

Table 2. Priorities of PDCs Demonstrating Coach, Player and Combined Comparisons

PlayerDevelopment

\begin{tabular}{lcccccc} 
Contexts (PDCs) & \multicolumn{2}{c}{ Combined $(\mathbf{n}=\mathbf{1 0})$} & \multicolumn{2}{c}{ Players $(\mathbf{n = 5})$} & \multicolumn{2}{c}{ Coaches $(\mathbf{n = 5})$} \\
\hline & Rank & Mean $(\mathbf{S D})$ & Rank & Mean $(\mathbf{S D})$ & Rank & Mean (SD) \\
\hline Training & 1 & $1.55(0.82)$ & 1 & $1.00(0)$ & 2 & $2.20(0.84)$ \\
\hline Game & 2 & $2.82(1.33)$ & 2 & $2.67(1.21)$ & 3 & $3(1.58)$ \\
\hline Personal & 3 & $3.00(1.41)$ & 4 & $4.00(0.89)$ & 1 & $1.80(0.84)$ \\
\hline Lifestyle & 4 & $3.09(1.14)$ & 3 & $2.83(0.75)$ & 4 & $3.40(1.52)$ \\
\hline Social & 5 & $5.18(0.98)$ & 5 & $5.00(1.10)$ & 6 & $5.40(0.89)$ \\
\hline School & 6 & $5.36(0.67)$ & 6 & $5.5(0.55)$ & 5 & $5.20(0.84)$
\end{tabular}

Table 3. Player Development Features - Lifestyle

Player Development

\begin{tabular}{|c|c|c|c|c|c|}
\hline Features (PDFs) & $(n=11)$ & & $n=6)$ & & $(n=5)$ \\
\hline Rank & Mean (SD) & Rank & Mean (SD) & Rank & $\overline{\text { Mean (SD) }}$ \\
\hline I am disciplined & $3.70(2.26)$ & 3 & $4.20(2.16)$ & 1 & $3.20(2.12)$ \\
\hline $\begin{array}{l}\text { I stay away from bad } \\
\text { influences of drink and drugs } 2\end{array}$ & $3.80(3.08)$ & 1 & $2.00(1.22)$ & 5 & $5.60(2.82)$ \\
\hline $\begin{array}{l}\text { I understand the dangers of } \\
\text { smoking and alcohol }\end{array}$ & $4.40(3.43)$ & 2 & $2.20(1.64)$ & 7 & $6.60(2.82)$ \\
\hline $\begin{array}{l}\text { I drink, sleep, eat and relax } \\
\text { appropriately }\end{array}$ & $4.90(1.44)$ & 5 & $5.40(1.34)$ & 3 & $4.40(1.41)$ \\
\hline $\begin{array}{l}\text { I am disciplined about my } \\
\text { rest and lifestyle }\end{array}$ & $5.00(2.62)$ & 5 & $5.40(1.51)$ & 4 & $4.60(0.70)$ \\
\hline $\begin{array}{l}\text { I am friendly to people } \\
\text { around me }\end{array}$ & $5.60(2.91)$ & 4 & $4.60(2.30)$ & 7 & $6.60(4.24)$ \\
\hline $\begin{array}{l}\text { I know I need to get adequate } \\
\text { rest and sleep to be successful } 7\end{array}$ & $6.30(2.90)$ & 9 & $8.40(0.89)$ & 2 & $4.20(3.53)$ \\
\hline $\begin{array}{l}\text { I mix with the right crowd of } \\
\text { friends that will be positive } \\
\text { towards my development } 8\end{array}$ & $6.80(2.25)$ & 7 & $7.00(2.54)$ & 7 & $6.60(1.41)$ \\
\hline $\begin{array}{l}\text { I treat people around me fairly } \\
\text { and keep my feet on the ground } 9\end{array}$ & $7.00(3.52)$ & 8 & $7.20(3.70)$ & 10 & $6.80(3.53)$ \\
\hline $\begin{array}{l}\text { I prepare effectively before } \\
\text { training and games }\end{array}$ & $7.40(2.17)$ & 9 & $8.40(2.50)$ & 6 & $6.40(0.00)$ \\
\hline
\end{tabular}


Table 4. Player Development Features - Personal

Player Development

Features (PDFs) Combined ( $\mathrm{n}=11) \quad$ Players $(\mathrm{n}=6) \quad$ Coaches $(\mathrm{n}=5)$

\begin{tabular}{|c|c|c|c|c|c|c|}
\hline & Rank & Mean (SD) & Rank & Mean (SD) & Rank & Mean (SD) \\
\hline I am disciplined & 1 & $3.30(0.00)$ & 2 & $2.80(2.95)$ & 1 & $3.80(3.53)$ \\
\hline I am determined & 2 & $3.40(3.52)$ & 1 & $2.60(2.07)$ & 3 & $4.20(1.41)$ \\
\hline I am motivated & 3 & $4.10(2.12)$ & 4 & $4.20(2.17)$ & 2 & $4.00(2.83)$ \\
\hline $\begin{array}{l}\text { I understand I should keep } \\
\text { away from the people } \\
\text { involved in things unhelpful } \\
\text { to becoming a pro }\end{array}$ & & & & & & \\
\hline (e.g. smoking and drinking) & 4 & $4.20(1.41)$ & 3 & $3.60(1.67)$ & 4 & $4.80(4.24)$ \\
\hline $\begin{array}{l}\text { I show strong character, } \\
\text { particularly when getting beat }\end{array}$ & & $6.10(2.83)$ & 5 & $5.00(1.22)$ & 9 & $7.20(4.24)$ \\
\hline $\begin{array}{l}\text { I listen to instructions and } \\
\text { respond appropriately }\end{array}$ & 6 & $6.30(2.83)$ & 7 & $7.00(2.83)$ & 6 & $5.60(1.41)$ \\
\hline I express myself & 7 & $6.60(1.41)$ & 9 & $8.00(2.34)$ & 5 & $5.20(2.10)$ \\
\hline I have an appetite to succeed & 8 & $6.70(0.71)$ & 6 & $6.80(1.48)$ & 8 & $6.60(1.41)$ \\
\hline $\begin{array}{l}\text { I have the mental strength to } \\
\text { cope with situations on and } \\
\text { off the pitch }\end{array}$ & 9 & $7.00(2.91)$ & 9 & $8.00(2.56)$ & 7 & $6.00(2.83)$ \\
\hline $\begin{array}{l}\text { I don't take my opportunities } \\
\text { for granted }\end{array}$ & 10 & $7.30(2.12)$ & 7 & $7.00(3.00)$ & 10 & $7.60(0.00)$ \\
\hline
\end{tabular}

Table 5. Player Development Features - Social

Player Development

\begin{tabular}{|c|c|c|c|c|c|c|}
\hline \multirow[t]{2}{*}{ Features (PDFs) } & \multicolumn{2}{|c|}{ Combined (n=11) } & \multicolumn{2}{|c|}{ Players $(n=6)$} & \multicolumn{2}{|c|}{ Coaches (n=5) } \\
\hline & Rank & Mean (SD) & Rank & Mean (SD) & Rank & Mean (SD) \\
\hline I elicit support from my & & & & & & \\
\hline parents when necessary & 1 & $3.90(3.34)$ & 2 & $4.00(3.53)$ & 2 & $3.80(3.56)$ \\
\hline I am responsible for myself & 2 & $4.00(3.55)$ & 3 & $5.20(4.02)$ & 1 & $2.80(2.94)$ \\
\hline I am disciplined about my & & & & & & \\
\hline rest and lifestyle & 3 & $4.80(2.52)$ & 4 & $5.40(3.43)$ & 3 & $4.20(1.30)$ \\
\hline I respect others & 4 & $5.10(3.21)$ & 1 & $3.80(2.77)$ & 7 & $6.40(3.36)$ \\
\hline $\begin{array}{l}\text { I take responsibility for my } \\
\text { own learning }\end{array}$ & 5 & $5.40(1.77)$ & 4 & $5.40(2.07)$ & 4 & $5.40(1.67)$ \\
\hline $\begin{array}{l}\text { I make good choices about } \\
\text { what I should be doing befor }\end{array}$ & & & & & & \\
\hline matches & 6 & $5.60(2.01)$ & 6 & $5.60(2.70)$ & 5 & $5.60(1.34)$ \\
\hline I am a polite young footballe & er 7 & $6.10(2.84)$ & 9 & $6.40(1.51)$ & 6 & $5.80(3.96)$ \\
\hline $\begin{array}{l}\text { I am sensible about what I } \\
\text { do with my downtime }\end{array}$ & 8 & $6.40(1.42)$ & 7 & $6.20(1.64)$ & 8 & $6.60(1.34)$ \\
\hline $\begin{array}{l}\text { I make the right choices to b } \\
\text { sensible away from training }\end{array}$ & 9 & $6.70(2.62)$ & 7 & $6.20(2.77)$ & 9 & $7.20(2.68)$ \\
\hline I relate to my parents & 10 & $7.00(3.91)$ & 10 & $6.80(4.43)$ & 9 & $7.20(3.83)$ \\
\hline
\end{tabular}


Table 6. Player Development Features - Game

Player Development

Features (PDFs)

Combined ( $\mathrm{n}=11)$

Players ( $\mathrm{n}=\mathbf{6})$

Coaches $(\mathrm{n}=\mathbf{5})$

\begin{tabular}{|c|c|c|c|c|c|c|}
\hline & Rank & Mean (SD) & Rank & Mean (SD) & Rank & $\overline{\text { Mean (SD) }}$ \\
\hline I am technically competent & 1 & $3.30(3.95)$ & 1 & $3.40(3.29)$ & 1 & $3.20(4.92)$ \\
\hline I understand the tactical & & & & & & \\
\hline demands of the game & 2 & $4.70(3.65)$ & 2 & $3.80(4.09)$ & 4 & $5.60(3.36)$ \\
\hline I understand the game & 3 & $4.50(2.07)$ & 4 & $4.40(1.14)$ & 2 & $4.60(2.88)$ \\
\hline I can keep possession & 4 & $4.90(3.51)$ & 3 & $4.20(3.77)$ & 4 & $5.60(3.51)$ \\
\hline $\begin{array}{l}\text { I apply what I've learnt in } \\
\text { training into the game }\end{array}$ & 5 & $5.90(3.00)$ & 6 & $6.40(3.78)$ & 3 & $5.40(2.30)$ \\
\hline $\begin{array}{l}\text { I can set the right standards } \\
\text { on the pitch }\end{array}$ & 6 & $6.00(2.62)$ & 5 & $4.80(0.84)$ & 8 & $7.20(3.35)$ \\
\hline $\begin{array}{l}\text { Itry different skills to make } \\
\text { things happen in a positive way }\end{array}$ & & $6.50(1.35)$ & 8 & $6.60(0.89)$ & 6 & $6.40(1.82)$ \\
\hline $\begin{array}{l}\text { I find solutions to } \\
\text { problems quickly }\end{array}$ & 8 & $6.70(1.83)$ & 6 & $6.40(1.14)$ & 7 & $7.00(2.45)$ \\
\hline $\begin{array}{l}\text { I respond/react in a positive } \\
\text { manner to any setbacks in } \\
\text { the game }\end{array}$ & 9 & $8.10(3.35)$ & 9 & $8.00(3.74)$ & 10 & $8.20(3.35)$ \\
\hline I am aware of space & 10 & $8.70(2.83)$ & 12 & $10.2(1.64)$ & 8 & $7.20(3.11)$ \\
\hline I set myself targets & 11 & $9.20(3.12)$ & 11 & $10.0(1.22)$ & 11 & $8.40(4.34)$ \\
\hline
\end{tabular}

Table 7. Player Development Features - Training

Player Development

Features (PDFs)

Combined ( $\mathrm{n}=11)$

Players $(\mathrm{n}=\mathbf{6})$

Coaches ( $\mathrm{n}=\mathbf{5})$

\begin{tabular}{|c|c|c|c|c|c|c|}
\hline & Rank & Mean (SD) & Rank & Mean (SD) & Rank & Mean (SD) \\
\hline I am for quality at all times & 1 & $3.77(3.15)$ & 2 & $3.80(4.20)$ & 2 & $3.75(1.70)$ \\
\hline I train like I play & 2 & $4.66(2.78)$ & 4 & $5.00(2.54)$ & 3 & $4.25(3.40)$ \\
\hline I find solutions to problems & 3 & $4.77(3.76)$ & 1 & $2.80(1.48)$ & 9 & $7.25(4.50)$ \\
\hline $\begin{array}{l}\text { I switch onto the training } \\
\text { environment as soon as I arrive }\end{array}$ & 4 & $5.00(3.00)$ & 8 & $6.40(2.70)$ & 1 & $3.25(2.62)$ \\
\hline I work on my weaknesses & 4 & $5.00(1.73)$ & 3 & $4.20(1.64)$ & 6 & $6.00(1.41)$ \\
\hline $\begin{array}{l}\text { I have the vision and drive to } \\
\text { work hard }\end{array}$ & 6 & $5.66(2.44)$ & 6 & $5.60(2.60)$ & 5 & $5.75(2.62)$ \\
\hline $\begin{array}{l}\text { I am disciplined in } \\
\text { maintaining my fitness }\end{array}$ & 7 & $6.33(2.69)$ & 7 & $6.20(2.77)$ & 8 & $6.50(3.00)$ \\
\hline $\begin{array}{l}\text { I respond to the coach's } \\
\text { instructions }\end{array}$ & 8 & $7.00(3.39)$ & 9 & $7.80(3.89)$ & 6 & $6.00(2.82)$ \\
\hline I play to my strengths & 9 & $7.33(2.39)$ & 10 & $9.20(0.44)$ & 4 & $5.00(1.41)$ \\
\hline $\begin{array}{l}\text { I can record what I have } \\
\text { done well and need to } \\
\text { improve on }\end{array}$ & 9 & $7.33(3.08)$ & 4 & $5.00(1.87)$ & 11 & $10.2(0.50)$ \\
\hline $\begin{array}{l}\text { I am a positive role model to } \\
\text { younger players }\end{array}$ & 11 & $9.11(3.48)$ & 11 & $10.0(2.23)$ & 10 & $8.00(4.76)$ \\
\hline
\end{tabular}


Table 8. Player Development Features - School

\begin{tabular}{|c|c|c|c|c|c|c|}
\hline \multirow[t]{2}{*}{$\begin{array}{l}\text { Player Development } \\
\text { Features (PDFs) }\end{array}$} & \multicolumn{2}{|c|}{ Combined (n=11) } & \multicolumn{2}{|c|}{ Players $(\mathrm{n}=6)$} & \multicolumn{2}{|c|}{ Coaches (n=5) } \\
\hline & Rank & Mean (SD) & Rank & Mean (SD) & Rank & Mean (SD) \\
\hline $\begin{array}{l}\text { I build a positive rapport } \\
\text { with teachers }\end{array}$ & 1 & $2.80(2.39)$ & 2 & $2.80(0.83)$ & 1 & $2.80(3.49)$ \\
\hline $\begin{array}{l}\text { I understand the privileged } \\
\text { position I am in but I intend } \\
\text { not to act differently to other } \\
\text { 'normal' pupils }\end{array}$ & 2 & $4.20(3.15)$ & 3 & $3.60(3.13)$ & 3 & $4.80(3.42)$ \\
\hline $\begin{array}{l}\text { I represent the Club in the } \\
\text { right way }\end{array}$ & 3 & $4.40(4.03)$ & 1 & $1.80(1.30)$ & 9 & $7.00(4.24)$ \\
\hline $\begin{array}{l}\text { I apply myself to school in a } \\
\text { range of ways }\end{array}$ & 4 & $5.20(2.14)$ & 4 & $5.00(2.82)$ & 4 & $5.40(1.51)$ \\
\hline $\begin{array}{l}\text { I complete my education to } \\
\text { achieve my potential }\end{array}$ & 4 & $5.20(1.81)$ & 5 & $5.80(1.30)$ & 2 & $4.60(2.19)$ \\
\hline $\begin{array}{l}\text { I integrate into school life, } \\
\text { making effective contribution }\end{array}$ & Is 6 & $5.70(1.25)$ & 6 & $6.00(0.70)$ & 4 & $5.40(1.67)$ \\
\hline $\begin{array}{l}\text { I conform with discipline } \\
\text { expectations at school }\end{array}$ & 7 & $5.80(2.14)$ & 7 & $6.20(2.38)$ & 4 & $5.40(2.07)$ \\
\hline $\begin{array}{l}\text { I seek advice and assistance } \\
\text { when required }\end{array}$ & 8 & $7.10(2.07)$ & 9 & $8.20(1.48)$ & 7 & $6.00(2.12)$ \\
\hline $\begin{array}{l}\text { I create a positive example } \\
\text { for the other students }\end{array}$ & 9 & $7.20(3.45)$ & 8 & $7.40(3.78)$ & 9 & $7.00(3.53)$ \\
\hline $\begin{array}{l}\text { I can listen and take new } \\
\text { information on board }\end{array}$ & 10 & $7.40(2.75)$ & 9 & $8.20(1.92)$ & 8 & $6.60(3.43)$ \\
\hline
\end{tabular}

\section{PERSONAL}

In a similar vain to the Lifestyle results, discipline features strongly as a PDF within the Personal context with strong agreement from both players and coaches as to its importance. Motivation and determination also feature highly in the ratings alongside keeping away from people involved in things unhelpful to becoming a professional player. Not taking opportunities provided for granted and elements of coping are less important to the development of players from both players' and coaches' perceptions. There is a marked difference between coaches and players in terms of showing 'strong character, particularly when getting beat' with players suggesting this is more important than the coaches.

SOCIAL

Parents feature heavily within this Context, although there seems to be conflicting evidence as to the importance of them in player development; while eliciting support from parents is rated as the highest combined score, relating with parents is rated as the lowest. Differences between coaches and players are most marked in terms of respect for others, with players rating this much higher than coaches. Discipline once again features highly.

GAME

Technical competence was the highest rated PDF of the Game from both the players' and 
coaches' perspectives. An understanding of the game, and specifically the tactical demands of the game, is also ranked highly. Dealing with decisions beyond the player's control in a disciplined manner and target setting are ranked lowest within the Game context.

TRAINING

Of all of the PDCs, players' and coaches' perceptions of the Training context are juxtaposed most markedly in a range of features including switching on to the training environment, playing to strengths, finding solutions to problems and recording achievements and goal setting. While coaches and players both agree that aiming for quality at all times is an important feature of Training, as a result of the large number of differences of opinion, other features such as 'I train like I play' are ranked highly but are less conclusive. However, there is agreement between coaches and players that being a positive role model to younger players is the least important PDF of Training.

\section{$\mathrm{SCHOOL}$}

Building a positive rapport with teachers achieved the highest combined ranking within the School context. There is also agreement between players and coaches in terms of understanding the privileged position that players are in and not intending to act differently to other 'normal' pupils. The greatest amount of disparity within the School context is the way in which players ranked the importance of representing the club in the right way as highest and coaches as the lowest.

\section{DISCUSSION}

The aim of this study was to explore how coaches and players perceived the key Player Development Contexts of an elite academy footballer. We also aimed to identify the constituent Player Development Features within each context; eliciting these perceptions was intended to help identify the core elements of a player profiling tool which was then to be used in formal and informal mentoring processes.

The results are important to the field because they derive from a visible, systematic and replicable process and because the participants were from one of the highest performing clubs in world football. This study also goes beyond traditional approaches to researching this area by exploring both the contexts and features of player development, and by 'lifting the veil' [23] on the critical features of player performance held by both coaches and players. Using the Delphi Technique also allowed us to refine generic observations of PDCs and PDFs, from the perspective of players and coaches. Forcing coaches and players to decide about importance also extends previous work that simply tabulates contexts and features and affords equal weighting to all elements [7,8].

\section{PLAYER DEVELOPMENT CONTEXTS (PDCs)}

There is general consistency between the PDCs that emerged from this study and the FA 'four-corner' model [16]. The model is designed around the most appropriate developmental features that might emerge through time spent playing football. It could reasonably be expected that policy built around this model would influence coaches' perceptions of the different aspects of a player. It may even influence, albeit to a lesser extent, those players involved in talent pathways that the policy has been designed to influence. That said, it must be noted that policy does not stand in isolation and policy implementation is "a complex, ongoing, always contested process, in which there are struggles over values, interests and definitions" [24]. 
The specific environmental demands of players being away from home, co-located with other players in the same school and sharing accommodation, is likely to have affected the inclusion of Lifestyle and School contexts in participants' responses. These clearly go beyond Simmons' [16] model, at least in name (i.e., some of these responses could be allied to Simmons' 'social' component). Technical and tactical elements of the model are reported within the Game context and feature prominently in the ratings identified in the current study, yet here they are represented as integral elements of a wider appreciation of the Game and not limited to the context of Training. Although there is some alignment to the broader principles of the four-corner model, simply framing the 'domains' of expertise had neither effectively informed nor overly influenced the participants of this study.

While there are clear differences between the coaches' and players' perceptions of PDCs and PDFs and the aspects of development stipulated within Simmons' model (implemented by the Football Association), there is greater alignment with the 5Cs model [25] (which has been adopted by Sports Coach UK [14]). Although the model refers to coach expertise and behaviours, its constituent elements bear resonance with the participants' notions of the contexts and features that are revealed here. For example, Competence traits are featured within Game and Training contexts and Confidence is regularly mentioned within the Personal context. Connection is clearly expressed in terms of building a positive rapport with schools and eliciting support from teachers, although forming relationships seems less of a priority. Character and Caring are less prominent; they are mentioned within the Lifestyle context but were poorly rated by both players and coaches. The most striking disparity between our findings and the 5Cs model is the infrequent mention of Creativity, with a combined ranking of $8^{\text {th }}$ in the Game context. In Training, it was also ranked $1^{\text {st }}$ by players but only $9^{\text {th }}$ by coaches.

The omission of Creativity from the current study is at odds with the attention paid to it as a disposition - in a range of participant and talent development models, particularly in educational domains [26] and in the guidance typically offered to coaches [15]. That said, 'finding solutions to problems' in Training, a trait often related to creativity [26], was highly rated by players $\left(1^{\text {st }}\right)$ and less so by coaches $\left(9^{\text {th }}\right)$. This lack of concern for Creativity, combined with the dominance of discipline, within the findings might point to a stifled coaching environment where players are expected to fit into pre-determined systems employed by the coaches. If this is the case, this is counterproductive to talent development as coaches are expected to offer practice variation and to encourage experimentation by players so they become versatile performers capable of responding to situations in innovative ways $[27,28]$. If the lack of creativity as a PDF were to be addressed, coaches delivering this developmental programme would need to facilitate a wider range of learning situations and task demands.

\section{PLAYER DEVELOPMENT FEATURES}

Overall, the findings illustrate some agreement between coaches and players on the central features that need to be developed through a football development programme. They also highlight discrepancies in other areas, especially regarding Training. Discipline featured prominently in half of the Contexts offered by participants, demonstrating the importance and multifaceted nature of this feature to both players and coaches. It is difficult to confirm that each respondent held the same meaning for 'discipline' across contexts; in Training, it may mean working hard throughout a session, whereas in Lifestyle it may relate more to avoiding bad influences. However, other studies in similar settings have demonstrated a heightened sense of discipline in youngsters involved in sport and report that students 
understood the reasons for their teachers maintaining discipline [29]. In this study, it seemed that elite coaches understood discipline as a factor that facilitated progression in youth soccer, while in other studies it can link more to obeying orders [30]. However, in studies exploring the development of athletes' wide-ranging competencies, it is noticeably absent [7, 31]. The research team did not expect this prominence, but given that the player-participants were located in a school context it is likely that the routine and expectations of a school environment will have contributed to this outcome. It is also plausible to suggest that the culture of courtesy and respect witnessed at the Academy engendered some of this awareness of the need for players to be disciplined. Further research is required to establish the exact nature of discipline within these environments.

The research brief entailed an understanding of which PDCs and PDFs were important as constituent elements of a player profiling tool that could be used within subsequent mentoring programmes. Player profiling has been recognised as having benefits for the athlete in the way that it allows them to target set and realise goals [32]. However, participants in the current study were not especially convinced of the benefits of target setting; while it was ranked highly enough to be included in the final round of scoring, players and coaches frequently ranked it low across a number of PDCs. This could be as a result of undervaluing target setting in previous player support programmes and ultimately the reason for the research being commissioned.

Findings relating to the role of parents and relationships between players and parents are also interesting. Previous studies have evidenced the crucial role that parents play in children's sports participation, motivation, and overall development [33, 34]. Kay [35] suggests the development of sporting excellence is a 'family affair', while another empirical study reported that both youth coaches and youth players emphasise the importance of the player's family in balancing sport and school [8]. In this research, both players and coaches rate eliciting support from parents highly. However, the ability of the player to form relationships with their family was poorly rated by both coaches and players; developing rapport with teachers was rated higher. Perceiving no real need to develop good relationships with parents may become problematic when they are called upon to offer some form of support. Given the critical role that parents can play, it is clear that further developmental work is required with players in this area.

Players and coaches agreed on the importance of determination, but were less united about the need for players to have the mental strength to cope with situations on and off the pitch. Both of these development features relate to mental toughness and have been detected before in a similar study exploring performance indicators [36]. While personal development features are recognised, there is a need to develop players' coping strategies so that they can adapt to the psychological demands of the game to optimise their own performance.

\section{LIMITATIONS}

It is clear that there are several limitations to this study. The Delphi technique was selected as a research tool, as the initiating problem identified by the club did not lend itself to precise analytical techniques. However, it is helpful for collating and ranking subjective judgments to identify a form of consensus. The themes that were collated were captured anonymously which meant that players, in particular, had an equal voice at this stage [37]. That said, the representativeness of the outcomes - as with any study with a limited sample size - is limited. Moreover, the coaches offered perspectives based upon unique positions within this Academy and are therefore also influenced by localised environmental factors. 
Although the players were selected specifically to represent the range of ages of players within the Academy, this also limits the potential to reach consensus as a result of the wide developmental discrepancies between these ages, which could lead to a false consensus. However, consensus was reached effectively and with relatively few rounds. This suggests that although the age range is wide, particularly with the inclusion of an 18 year old player in the sample, perspectives are shared and not disparate. Even though the unique environment experienced by the sample of scholarship players (e.g., schooled collectively, accommodated away from home) will have influenced their contributions, the findings still help to lift the veil on some of the issues that play out in the talent development programmes of elite football.

\section{RECOMMENDATIONS}

The notion of 'discipline' emerged as a prominent theme within this research; both the coaches and players prioritised it as important in developmental terms. However, the precise nature of discipline remains unclear, with the recurring use of the term by participants within this research only highlighting its perceived influence on the development of talent. However, the paucity of empirical research focusing upon discipline prompts us to call for further exploration of the concept in relation to player development within talent pathways.

While we have proposed a relationship between discipline and creativity, we also recognise a need for further research exploring a more detailed understanding of the prevalence of creativity in talent development environments. The relevance and prioritisation of PDCs and PDFs articulated within this paper will presumably continue to be acknowledged to varying degrees by coaches. The pressing implication for applied practice, therefore, is for coaches and coach educators to clarify how they define and value PDCs and PDFs within the context of talent development.

From a more practical perspective, the findings from this research also prompt us to question how talent development managers allocate - and prioritise - resources and provide developmental activities according to the PDFs. In this study, context-specific PDFs were prioritised, meaning that a subsequent line of enquiry could review the opportunities afforded within talent development systems for the development of such attributes.

Academies need to be aware of the disparity that exists between players and coaches in relation to which aspects of player development are more important than others. In the interest of maintaining positive coach-athlete dialogues, closing the gap on any potential misunderstanding is important. Academies also need to make more explicit those PDFs that are most critical for an individual player's development and ensure that regular mentoring opportunities exist to achieve appropriate exposure to these developmental experiences. Parental support workshops could also be offered to inform both players and parents of how each can work - within the family - to benefit both performance and development.

\section{CONCLUSION}

This study offered a glimpse of the inner workings of an elite football Academy of one of the most prestigious clubs in world football. As such, the findings illustrate what coaches and players perceive to be the most important developmental features of talented Academy footballers. The research also highlights the contexts in which these features are manifest at the highest level. The prevalence of discipline in both sets of participants' perceptions suggests further exploratory research is required in this area to provide a more detailed understanding of the specific significance of this feature in developing talented players.

The Delphi polling technique we used provided an ideal platform for identifying 
important themes and for establishing consensus. It also seemed to engender a strong sense of player and coach engagement. It would be interesting to observe the use of the final PDCs and PDFs in an applied sense within the Academy and whether this consensus remained. Ultimately, this research has identified coaches' and players' perceptions on the importance of Player Development Contexts and Features for developing talented footballers in an elite football Academy.

\section{ACKNOWLEDGEMENTS}

Thanks to the Head of Education and Welfare and coaches at the Club for supporting the research aims and to Ian Greenwood, Graham Turner and Stephen Potter for contributing to data capture and analysis. We would also like to thank Donna O'Connor and Arnold LeUnes for their valuable contribution to the article through the review process.

\section{REFERENCES}

1. Wylleman, P., Alfermann, D. and Lavallee, D., Career Transitions in Sport: European Perspectives, Psychology of Sport and Exercise, 2004, 5, 7-20

2. Abbott, A. and Collins, D., Eliminating the Dichotomy Between Theory and Practice in Talent Identification and Development: Considering the Role of Psychology, Journal of Sports Sciences, 2004, 22, 395-408.

3. Bailey, R. and Morley, D., Towards a Model of Talent Development in Physical Education, Sport, Education and Society, 2006, 11, 211-230.

4. Baker, J. and Schorer, J., Identification and Development of Talent in Sport: Introduction to the Special Issue, Talent Development \& Excellence, 2010, 2(2), 119-121.

5. Balyi, I., Long Term Athlete Development - The System and Solutions, Faster, Higher, Stronger, 2002, 14, 6-9.

6. Simonton, D.K., Talent and its Development: An Emergenic and Epigenetic Model, Psychological Review, 1999, 106(3), 435-457.

7. Strachan, L., Côté, J. and Deakin, J., A New View: Exploring Positive Youth Development in Elite Sports Contexts, Qualitative Research in Sport, Exercise and Health, 3(1), 9-32.

8. Larsen, C. H., Alfremann, D. and Christensen, M. K., Psychosocial Skills in a Youth Soccer Academy: A Holistic Ecological Perspective, Sport Science Review, 2012, 21(3-4), 51-75.

9. Butler, R. J. and Hardy, L., The Performance Profile: Theory and Application, The Sport Psychologist, 1992, $6,253-264$

10. Kelly, G.A., The Psychology of Personal Constructs: A Theory of Personality, Vol. 1, Routledge, London, 1991 (Original Work Published 1955).

11. Jones, G., The Role of Performance Profiling in Cognitive Behavioral Interventions in Sport, The Sport Psychologist, 1993, 7, 160-172.

12. Toering, T.T., Elferink- Gemser, M. T., Jordet, G., and Visscher. C., Self-Regulation and Performance Level of Elite and Non-Elite Youth Soccer Players, Journal of Sports Sciences, 2009, 27, 1509-1517.

13. Department for Education, Physical Education: Key Stage 3 Program of Study, Retrieved from: Http://www.education.gov.uk/schools/teachingandlearning, 2007.

14. Sports Coach UK, The UK Coaching Framework: A 3-7-11 Year Action Plan, National Coaching Foundation, 2008.

15. Haskins, D., Coaching the Whole Child: Positive Development Through Sport, Coachwise, Leeds, 2011.

16. Simmons, C., Fast Tracking and Player Development, Insight, 2004, 3(7), 24-25.

17. Roddy, G., The Elite Player Performance Plan, Retrieved from Http://www.premierleague.com/engb/youth/elite-player-performance-plan.html., 2011.

18. The Premier League, The Elite Player Performance Plan, The Premier League, London, 2011. 
19. Robson, C., Real World Research, $2^{\text {nd }}$ edn., Blackwell, Oxford, 2002, 260-268.

20. Hsu, C.C. and Sandford, B.A., The Delphi Technique: Making Sense Of Consensus, Practical Assessment, Research \& Evaluation, 2007, 12(10),1-8.

21. Beech, B., Go the Extra Mile - Use the Delphi Technique, Journal of Nursing Management, 1999, 7, 281288.

22. Morley, D. and Bailey, R. Talent in Sport, in Talbot, M., Haag, H. and Keskinen, K., eds., Directory of Sport Science, $6^{\text {th }}$ edn., ICSSPE, Berlin, 2013, 301-310.

23. Seale, C., The Quality of Qualitative Research, Sage, London, 1999, 2-7.

24. Penney, D. and Evans, J., Policy, Power and Politics in Physical Education, in Green, K. and. Hardman, K., eds., Physical Education: Essential Issues, Sage, London, 2005, 21-38.

25. Lerner, R. M., Lerner, J. V., Almerigi, J., Theokas, C., Phelps, E., Gestsdottir, S. Naudeau, S., Jelicic, H., Alberts, A. E., Ma, L., Smith, L. M., Bobek, D. L., Richman-Raphael, D., Simpson, I., Christiansen, E. D. and von Eye, A., Positive Youth Development, Participation in Community Youth Development Programs, and Community Contributions of Fifth Grade Adolescents: Findings from the First Wave of the 4-H Study of Positive Youth Development. Journal of Early Adolescence, 2005, 25(1), 17-71.

26. Cropley, A.J., Actualizing Creative Intelligence, in: Freeman, J., Span, P. and Wagner. H., eds., Actualizing Talent: A Lifelong Challenge, Cassell, London, 1995, 99-114.

27. Morley, D. and Bailey, R. P., Modelling Long-term Athlete Development in Sport, in: Navin, A., ed., Sports Coaching: A Reference Guide for Students, Coaches and Competitors, Crowood Press, Marlborough, 2011, 112-118.

28. Abernethy, B., Developing Expertise in Sport- How Research can Inform Practice, in: Farrow, D., Baker, J. and MacMahon, C., eds., Developing Sport Expertise: Researchers and Coaches put Theory Into Practice, Routledge, Oxford, 2008, 1-14.

29. Bakirtzoglou, P. and Ioannou, P., Discipline of Greek Students in Relation to Gender, Interest in Physical Education Lessons and Sport Activity, SportLogia, 2011, 7(2), 182-197.

30. Holt, N. L. and Dunn, J. G. H., Toward a Grounded Theory of the Psychosocial Competencies and Environmental Conditions Associated with Soccer Success, Journal of Applied Sport Psychology, 2004, 16, 199-219.

31. Oliver, E.J., Hardy, J. and Markland. D., Identifying Important Practice Behaviors for the Development of High-level Youth Athletes: Exploring the Perspectives of Elite Coaches, Psychology of Sport and Exercise, 2010, 11, 433-443.

32. Nicholls, A. and Jones, L., Psychology in Sports Coaching: Theory and Practice, Routledge, London, 2013, 98-106.

33. Brustad, R. J., Integrating Socialization Influences into the Study of Children's Motivation in Sport, Journal of Sport and Exercise Psychology, 1992, 14, 59-77.

34. Anderson, C. B., Hughes, S. O. and Fuemeller, B. F., Parent-Child Attitude Congruence in Type and Intensity of Physical Activity: Testing Multiple Mediators of Sedentary Behaviours in Older Children, Health psychology, 2009, 28(4), 428-438.

35. Kay, T., Sporting Excellence: a Family Affair?, European Physical Education Review, 2000, 6(2), 151-169.

36. Cupples, B. and O'Connor, D., The Development of Position-Specific Performance Indicators in Elite Youth Rugby League: A Coach's Perspective, International Journal of Sports Science and Coaching, 2011, 6(1), 125-141.

37. Linstone, H. A., The Delphi Technique, in Fowlers, J., ed., Handbook of Futures Research, Greenwood Press, Westport, CT, 1978, 273- 300. 